\title{
Effects of Er:YAG Laser Compared to Ultrasonic Scaler in Periodontal Treatment: A 2-Year Follow-Up Split-Mouth Clinical Study
}

\author{
Roberto Crespi, * Paolo Capparè, * Isabel Toscanelli, * Enrico Gherlone, * and George E. Romanos ${ }^{\dagger \dagger}$
}

Background: The aim of this clinical study was to compare the results of non-surgical treatment of periodontal disease with an erbium-doped:yttrium, aluminum, and garnet (Er:YAG) laser to root debridement with an ultrasonic scaler.

Methods: Twenty-five patients furnished two quadrants containing four teeth with probing depths (PD) $>4 \mathrm{~mm}$; the quadrants were divided equally between the right and left sides. On one side, teeth were treated by Er:YAG laser using $160 \mathrm{~mJ} /$ pulse at $10 \mathrm{~Hz}$ (test group); on the contralateral side, teeth were treated by ultrasonic scaler (control group). Clinical baseline data, including plaque index, gingival index, probing depth (PD), and clinical attachment level (CAL), were recorded before treatment and at 3 months and 1 and 2 years.

Results: There were statistically significant differences in PD between the test and control groups for pockets of 1 to $4 \mathrm{~mm}$ $(P<0.05), 5$ to $6 \mathrm{~mm}(P<0.01)$, and $\geq 7 \mathrm{~mm}(P<0.001)$. However, there were no significant differences between the test and control groups for CAL gain in pockets of 1 to $4 \mathrm{~mm}$; statistically significant differences were found between the test and control groups in pockets of 5 to $6 \mathrm{~mm}(P<0.01)$ and $\geq 7 \mathrm{~mm}$ $(P<0.001)$.

Conclusion: Er:YAG laser periodontal treatment resulted in statistically significant improvements in PD and CAL gain compared to ultrasonic scaler treatment at 2-year follow-up, especially in moderate and deep pockets. J Periodontol 2007; 78:1195-1200.

\section{KEY WORDS}

Dental scaling; laser; periodontal disease; therapy.

\footnotetext{
* Department of Dentistry, Vita Salute University, San Raffaele Hospital, Milan, Italy.

$\dagger$ Department of Periodontology and Implant Dentistry, College of Dentistry, New York University, New York, NY.

‡ Department of Oral Surgery and Implant Dentistry, Dental School Frankfurt, Frankfurt, Germany.
}

$\Delta$ major goal of periodontal therapy is to achieve a biocompatible root surface through the removal of bacterial biofilms and smear layer. ${ }^{1-3}$ Ultrasonic scalers and hand instrumentation are the most commonly used procedures for root debridement in periodontal therapy. ${ }^{4}$ To achieve more efficient subgingival instrumentation at deeper probing depths (PDs), the tips of scalers have evolved to smaller diameters and longer working lengths. Clinical studies reported similar results when comparing ultrasonic scalers and manual instrumentation for root debridement, ${ }^{5-8}$ even though manual instrumentation requires more time and physical effort. ${ }^{9}$

Mechanical root debridement results in a smear layer containing bacteria, bacterial endotoxins, and contaminated root cementum. Furthermore, it does not remove plaque and calculus completely from interradicular septa and root concavities. ${ }^{10}$ Individually or collectively, these factors are likely to hamper the periodontal healing process. ${ }^{11} \mathrm{~A}$ significant disadvantage of ultrasonic scalers, for the patient and the clinician, is the formation of a contaminated aerosol. ${ }^{12}$

In recent years, erbium-doped:yttrium, aluminum, and garnet (Er:YAG) laser radiation has been suggested as an alternative instrumentation modality for the treatment of chronic periodontitis. 
In vitro studies ${ }^{13,14}$ reported effective results for $\mathrm{Er}$ : YAG laser root debridement. When used at lowenergy densities with a water spray surface coolant, the Er:YAG laser provides a homogeneous and smooth root surface topography. ${ }^{15-18}$ In addition, the laser is effective at removing dental calculus ${ }^{19,20}$ and smear layer and exhibits bactericidal effects ${ }^{21,22}$ without inflicting any significant thermal damage to the root surface. ${ }^{23,24}$

Several clinical studies ${ }^{25-27}$ compared traditional instrumentation to the Er:YAG laser for treatment of periodontal disease. However, laser usage for such purposes remains controversial, probably because of insufficient evidence that any specific wavelength of laser is superior to traditional instrumentation. The lack of evidence supporting laser usage results from poorly designed studies and the lack of continuity of design between studies, e.g., wide variations in laser parameters, energy densities, experimental designs, and the lack of proper controls in many studies. ${ }^{28}$

Consequently, the goal of this study was to compare the results of non-surgical treatment of chronic periodontitis with an Er:YAG laser to ultrasonic scaler debridement of root surfaces.

\section{MATERIALS AND METHODS}

\section{Patient Selection}

The study group consisted of 15 females and 10 males with a mean age of 53 years (range: 37 to 65 years) who had moderate to advanced chronic periodontitis. The study was conducted in a private office between 2004 and 2006 in accordance with the Helsinki Declaration of 1975 , as revised in 2000 . Following a thorough explanation of the study and treatment procedures, all patients signed an informed consent. The criteria for patient selection were good general health, no use of systemic antibiotics during the 6 months prior to the study, and no periodontal therapy in the 12 months preceding the study.

\section{Study Design}

The study followed a split-mouth design. Pockets with PD $>4 \mathrm{~mm}$ were included in the study. Fifty quadrants (30 in the maxillary jaw; 20 in the mandibular jaw), for a total of 200 teeth (130 single-rooted and 70 multirooted) and 1,200 sites, were divided equally between the right and left sides. On one side, teeth were treated by Er:YAG laser (ERL; test group), whereas teeth of the contralateral side were treated by ultrasonic scaler (UI; control group). Two weeks before root debridement, all patients were seen by a dental hygienist for a supragingival cleaning of the teeth and instructions in oral hygiene. After treatment, the same procedure was performed every 6 months for 2 years.

\section{Treatment}

In the control group (UI), an ultrasonic scaler ${ }^{\S}$ with a straight and/or curved metal tip insert was used under constant water irrigation, according to the manufacturer's instructions.

In the test group (ERL), an Er:YAG laser system" (wavelength $2.94 \mu \mathrm{m}$ ) was used at $160 \mathrm{~mJ} /$ pulse and $10 \mathrm{~Hz}$, yielding an equivalent energy density of $94 \mathrm{~J} / \mathrm{cm}^{2} /$ pulse. ${ }^{16}$

The Er:YAG laser beam was delivered into the periodontal pockets using a chisel-shaped quartz tip with a diameter of $400 \mu \mathrm{m}$ " in contact mode under water irrigation, from a coronal to an apical direction with the tip inclined at $10^{\circ}$ to $15^{\circ}$ to the root surfaces.

Root instrumentation for both groups was carried out until the clinician felt a smooth surface on the roots. The working time required was 4 minutes for the UI group and 5 minutes for the ERL group for single-rooted teeth and 9 minutes (for both groups) for multirooted teeth. All treatments were performed by the same clinician.

\section{Data Collection}

The baseline data were recorded before treatment and at 3 months and 1 and 2 years following treatment. The data collection was performed by the same blinded and calibrated investigator.

Clinical measurements were taken at six points around each tooth: mesio-lingual, mesio-facial, facial, disto-facial, disto-lingual, and lingual.

The following clinical parameters were measured: plaque index $(\mathrm{PI}),{ }^{29}$ gingival index $(\mathrm{GI}),{ }^{29} \mathrm{PD}$, and clinical attachment level (CAL). PD was determined with a calibrated conventional periodontal probe, and PDs were grouped into those between 5 and 6 $\mathrm{mm}$ and those $\geq 7 \mathrm{~mm}$.

\section{Intraexaminer Reliability}

Four patients, each with two contralateral teeth with PDs $>5 \mathrm{~mm}$, were used to calibrate the examiner. The examiner evaluated the patients at two appointments that were separated by 5 days. Calibration was accepted if the data at baseline and 5 days later were similar at a $>90 \%$ level. This procedure was repeated periodically during the 2-year study period.

\section{Statistical Analysis}

A software package was used for the statistical analysis. * *

The paired $t$ test was used to compare the mean values between the control (UI) and test groups (ERL). In particular, comparisons were made for PD

\footnotetext{
$\S$ KaVo Dental Bismarckring, Biberach, Germany

HOYA ConBio, Fremont, CA.

I HOYA ConBio.

\# PCP 12, Hu-Friedy, Chicago, IL.

** SPSS version 9.0, SPSS, Chicago, IL.
} 
and CAL at baseline and 3 months, 1 year, and 2 years after surgery.

A paired $t$ test was performed to compare the intragroup mean values at different time points.

The alpha error was set at 0.05 . Data are presented as means \pm SD. The power of the study, given $1 \mathrm{~mm}$ as a significant difference between groups, was calculated to be 0.99 .

\section{RESULTS}

\section{Clinical Parameters}

Mean PI values are reported in Table 1. There were no significant differences between the UI and ERL groups at any time point. No statistically significant differences within the groups were found.

Mean GI values are reported in Table 1. There were no statistically significant differences between the UI and ERL groups at any time point; however, there were significant differences within the groups. In par- ticular, statistically significant differences were found in the UI group between baseline and 3 months and between 3 months and 1 year $(P<0.05)$. Statistically significant differences also were found in the ERL group between baseline and 3 months and between 3 months and 1 year $(P<0.05)$.

Changes in PD for the 5- to 6-mm pockets are reported in Table 2. There were statistically significant differences between the $\mathrm{UI}$ and ERL groups at 3 months post-treatment $(P<0.05)$ and at 1 and 2 years $(P<0.01)$. In addition, the UI group showed a statistically significant difference in PD between baseline and 3 months post-treatment $(P<0.01)$, but no difference was seen between 3 months and 1 year or between 1 -year and 2-year data.

For the ERL group, a statistically significant difference was noted between baseline and 3 months posttreatment $(P<0.001)$. This significant difference was maintained throughout the 2 -year study period. The

Table I.

\section{PI and GI Values From Baseline to 2 Years ( $N=50$ quadrants)}

\begin{tabular}{|c|c|c|c|c|c|c|c|c|c|c|c|}
\hline & \multicolumn{2}{|c|}{ Baseline } & \multicolumn{3}{|c|}{3 Months } & \multicolumn{3}{|c|}{ I Year } & \multicolumn{3}{|c|}{2 Years } \\
\hline & Mean & SD & Mean & $\Delta$ & $\mathrm{SD}$ & Mean & $\Delta$ & SD & Mean & $\Delta$ & SD \\
\hline \multicolumn{12}{|l|}{$\mathrm{PI}$} \\
\hline UI & 1.05 & 0.51 & 0.74 & 0.31 & 0.34 & 1.27 & -0.22 & 0.64 & 1.28 & -0.23 & 0.65 \\
\hline $\mathrm{ERL}$ & 1.05 & 0.51 & 0.81 & 0.24 & 0.42 & 1.26 & -0.21 & 0.57 & 1.29 & -0.24 & 0.48 \\
\hline$P$ value* & \multicolumn{2}{|c|}{ NS } & \multicolumn{3}{|c|}{ NS } & \multicolumn{3}{|c|}{ NS } & \multicolumn{3}{|c|}{ NS } \\
\hline UI & 1.75 & 0.58 & 0.49 & 1.26 & 0.45 & 0.63 & 1.12 & 0.35 & 1.01 & 0.74 & 0.76 \\
\hline ERL & 1.75 & 0.58 & 0.51 & 1.24 & 0.34 & 0.64 & 1.11 & 0.42 & 1.09 & 0.66 & 0.61 \\
\hline$P$ value* & \multicolumn{2}{|c|}{ NS } & \multicolumn{3}{|c|}{ NS } & \multicolumn{3}{|c|}{ NS } & \multicolumn{3}{|c|}{ NS } \\
\hline
\end{tabular}

NS = not significant

* $P$ value refers to differences between the test and control groups.

Table 2.

PD and CAL From Baseline to 2 Years in Pockets 5 to $6 \mathrm{~mm}$ ( $\mathrm{N}=50$ quadrants)

\begin{tabular}{|c|c|c|c|c|c|c|c|c|c|c|c|}
\hline & \multicolumn{2}{|c|}{ Baseline } & \multicolumn{3}{|c|}{3 Months } & \multicolumn{3}{|c|}{ I Year } & \multicolumn{3}{|c|}{2 Years } \\
\hline & Mean & SD & Mean & $\Delta$ & SD & Mean & $\Delta$ & SD & Mean & $\Delta$ & SD \\
\hline UI & 5.12 & 0.39 & 3.62 & 1.50 & 0.52 & 4.02 & 1.10 & 0.65 & 4.12 & 1.00 & 0.74 \\
\hline ERL & 5.49 & 0.27 & 2.91 & 2.58 & 0.56 & 2.60 & 2.89 & 0.37 & 2.61 & 2.88 & 0.54 \\
\hline$P$ value* & \multicolumn{2}{|c|}{ NS } & \multicolumn{3}{|c|}{$<0.05$} & \multicolumn{3}{|c|}{$<0.01$} & \multicolumn{3}{|c|}{$<0.01$} \\
\hline UI & 6.18 & 0.42 & 5.07 & 1.11 & 0.62 & 4.89 & 1.29 & 0.55 & 4.86 & 1.32 & 0.52 \\
\hline $\mathrm{ERL}$ & 6.27 & 0.51 & 3.64 & 2.63 & 0.83 & 3.32 & 2.95 & 0.64 & 3.35 & 2.92 & 0.91 \\
\hline$P$ value* & \multicolumn{2}{|c|}{ NS } & \multicolumn{3}{|c|}{$<0.01$} & \multicolumn{3}{|c|}{$<0.01$} & \multicolumn{3}{|c|}{$<0.01$} \\
\hline
\end{tabular}

NS = not significant.

* $P$ value refers to differences between the test and control groups. 
results confirm the long-term stability of PD in the UI and ERL groups.

Changes in CAL for the group of pockets with 5- to 6-mm PD are reported in Table 2. Statistically significant differences were found between the UI and ERL treatment groups at 3 months, 1 year, and 2 years post-treatment $(P<0.01)$. Within the UI group, differences were noted between baseline and 3 months post-treatment $(P<0.001)$. A similar difference was noted within the ERL group, i.e., between baseline and 3 months post-treatment $(P<0.05)$. These results seem to confirm the stability of CAL in both treatment groups over the study period.

The response of pockets with PD $\geq 7 \mathrm{~mm}$ showed that both treatments significantly reduced PDs during the 2 years of the study (Table 3 ). Differences were noted between the UI and ERL treatment groups at baseline versus 3 months post-treatment $(P<0.05)$ and at 1 and 2 years $(P<0.001)$. The UI treatment group showed a significant difference only when baseline data were compared to that at 3 months post-treatment $(P<0.001)$. Similarly, the ERL group showed a significant difference when baseline data were compared to that at 3 months post-treatment $(P<0.001)$ and when 3 -month data were compared to 1 -year data $(P<0.05)$.

Changes in CAL for the group of pockets with PD $\geq 7$ $\mathrm{mm}$ are reported in Table 3. There were statistically significant differences between the UI and ERL groups at 3 months post-treatment and after 1 and 2 years $(P<0.001)$. Within the UI treatment group, the only significant difference in CAL was seen when baseline data were compared to that at 3 months post-treatment $(P<0.001)$. However, within the ERL group, significant differences were noted between baseline data and data at 3 months $(P<0.001)$ and between 3 -month data and data at 1 year post-treatment
$(P<0.05)$. These results seem to show stability of CAL following the use of the Er:YAG laser in pockets with PD $\geq 7 \mathrm{~mm}$.

\section{DISCUSSION}

The results of the present study indicated that nonsurgical periodontal therapy using the Er:YAG laser or the ultrasonic scaler provided reductions in PD and gains in CAL that remained stable for more than 2 years following treatment.

However, the use of the Er:YAG laser resulted in a statistically significant and consistently greater reduction in PD over the 2-year study period for pockets of 5 to $6 \mathrm{~mm}(P<0.01)$ and pockets $\geq 7 \mathrm{~mm}(P<0.001)$ compared to the control groups (UI). Significant differences also were found in CAL gains for the ERL group compared to the UI treatment group, i.e., for pockets of 5 to $6 \mathrm{~mm}(P<0.01)$ and for pockets $\geq 7$ $\mathrm{mm}(P<0.001)$.

In another clinical study, ${ }^{25} 20$ patients with moderate to advanced periodontal disease were treated randomly in a split-mouth design with subgingival debridement using an Er:YAG laser $(160 \mathrm{~mJ} /$ pulse, $10 \mathrm{~Hz}$ ) or an ultrasonic instrument in pockets exhibiting a probing depth of $>4 \mathrm{~mm}$. There were no differences between the two groups in any of the measured clinical parameters at baseline. The sites treated with Er:YAG laser demonstrated a mean CAL gain of 1.48 $\pm 0.73 \mathrm{~mm}(P<0.001)$ and $1.11 \pm 0.59 \mathrm{~mm}(P<0.001)$ at 3 and 6 months, respectively. The sites treated by the ultrasonic device demonstrated a mean CAL gain of $1.53 \pm 0.67 \mathrm{~mm}(P<0.001)$ and $1.11 \pm 0.46 \mathrm{~mm}$ $(P<0.001)$ at 3 and 6 months, respectively. There were no statistically significant differences between the groups $(P>0.05)$.

Tomasi et al. ${ }^{30}$ compared the use of an Er:YAG laser at $160 \mathrm{~mJ}$ with a pulse frequency of $10 \mathrm{~Hz}$ to an

Table 3.

PD and CAL From Baseline to 2 years in Pockets $\geq 7 \mathrm{~mm}$ ( $\mathrm{N}=50$ quadrants)

\begin{tabular}{|c|c|c|c|c|c|c|c|c|c|c|c|}
\hline & \multicolumn{2}{|c|}{ Baseline } & \multicolumn{3}{|c|}{3 Months } & \multicolumn{3}{|c|}{ I Year } & \multicolumn{3}{|c|}{2 Years } \\
\hline & Mean & SD & Mean & $\Delta$ & SD & Mean & $\Delta$ & SD & Mean & $\Delta$ & SD \\
\hline \multicolumn{12}{|l|}{$\mathrm{PD}(\mathrm{mm})$} \\
\hline UI & 7.13 & 0.53 & 4.54 & 2.59 & 0.41 & 4.82 & 2.31 & 0.37 & 4.85 & 2.28 & 0.64 \\
\hline ERL & 7.92 & 0.78 & 3.91 & 4.01 & 0.59 & 3.11 & 4.81 & 0.41 & 3.05 & 4.87 & 0.53 \\
\hline$P$ value* & \multicolumn{2}{|c|}{$<0.05$} & \multicolumn{3}{|c|}{$<0.05$} & \multicolumn{3}{|c|}{$<0.001$} & \multicolumn{3}{|c|}{$<0.001$} \\
\hline \multicolumn{12}{|l|}{ CAL (mm) } \\
\hline UI & 8.35 & 0.33 & 5.96 & 2.39 & 0.93 & 6.33 & 2.02 & 0.61 & 6.34 & 2.01 & 0.92 \\
\hline ERL & 8.41 & 0.47 & 4.40 & 4.01 & 0.81 & 3.31 & 5.10 & 1.01 & 3.38 & 5.03 & 0.79 \\
\hline$P$ value* & \multicolumn{2}{|c|}{ NS } & \multicolumn{3}{|c|}{$<0.001$} & \multicolumn{3}{|c|}{$<0.001$} & \multicolumn{3}{|c|}{$<0.001$} \\
\hline
\end{tabular}

NS = not significant

*P value refers to differences between the test and control groups. 
ultrasonic scaler in a study of subgingival debridement. At 1 month post-treatment, the PD reduction was significantly greater for the test versus control sites $(0.9 \mathrm{~mm}$ versus $0.5 \mathrm{~mm} ; P<0.05)$. The CAL gain also was significantly greater $(0.5 \mathrm{~mm}$ versus 0.06 $\mathrm{mm} ; P<0.01)$. At the 4 -month examination, no significant differences were noted in PD reduction $(1.1 \mathrm{~mm}$ versus $1.0 \mathrm{~mm}$ ) or CAL gain $(0.6 \mathrm{~mm}$ versus $0.4 \mathrm{~mm})$. Both treatments resulted in reductions of the subgingival microflora. No significant differences in microbiologic composition were identified between the treatment groups at various time intervals The results of this study failed to demonstrate any apparent advantage of using an Er:YAG laser for subgingival debridement.

Schwarz et al. ${ }^{27}$ compared the use of an Er:YAG laser at an energy level of $160 \mathrm{~mJ} /$ pulse and $10 \mathrm{~Hz}$ to scaling and root planing in a split-mouth design for treatment of 20 patients with moderate to advanced periodontal disease with a 2-year follow-up. At both follow-up visits ( 1 and 2 years), they observed significant differences for the CAL $(P<0.001)$ between the two treatment groups, concluding that the CAL gain obtained following non-surgical periodontal treatment with the Er:YAG laser or scaling and root planing could be maintained over a 2 -year period.

A histologic study by Frentzen et al. ${ }^{31}$ compared the effect of Er:YAG laser irradiation of diseased root surfaces to root debridement by ultrasonic instrumentation. Ultrasonic instrumentation resulted in a smooth root surface covered by a smear layer, whereas the Er:YAG laser induced microstructural changes and a relatively rough surface topography. Crespi et al. ${ }^{32}$ reported that Er:YAG-treated root surfaces that were slightly roughened promoted in vitro fibroblast attachment and spreading. Thus, a roughened root surface might account for the improved CAL observed in the laser-treated specimens in the present study. In that study, 60 specimens obtained from 30 single-rooted human periodontally involved teeth were assigned randomly to treatment by ultrasonic scaler or by Er: YAG laser at $160 \mathrm{~mJ} /$ pulse at $10 \mathrm{~Hz}$. All of the specimens were incubated in Petri dishes with fibroblasts suspension and observed by scanning electron microscopy. Laser-treated specimens exhibited a significantly greater density of cells $\left(3,720 \pm 316\right.$ cells $/ \mathrm{mm}^{2}$ versus $658 \pm 140$ cells $\left./ \mathrm{mm}^{2}\right)$. Differences between both groups were statistically significant $(P<0.0001)$. Removal of the smear layer and etching of the root surface to produce a uniform roughness explains the increased fibroblast attachment, which, in turn, may be a partial explanation for the improved PD and CAL.

Schwarz et al. ${ }^{33}$ presented 2-year results following non-surgical periodontal treatment with an Er:YAG laser or scaling and root planing. Both groups showed a significant increase in cocci and non-motile rods and a decrease in the amount of spirochetes. Statistical analysis revealed a significant difference in CAL $(P<0.001)$ between the two treatment groups.

\section{CONCLUSIONS}

Given the conflicting results of the various clinical and in vitro studies, differences in study designs, and choice of laser parameters, there is a great need for an evidence-based clinical approach to the application of lasers in the treatment of chronic periodontitis. ${ }^{28}$

\section{ACKNOWLEDGMENT}

Drs. Crespi, Capparé, Toscanelli, Gherlone, and Romanos report no conflicts of interest related to this study.

\section{REFERENCES}

1. O'Leary TJ. The impact of research on scaling and root planing. J Periodontol 1986;57:69-75.

2. Aleo JJ, De Renzis FA, Farber PA, Varboncoeur AP. The presence and biological activity of cementumbound endotoxin. J Periodontol 1974;45:672-675.

3. Hatfield CG, Baumhammers A. Cytotoxic effects of periodontally involved surfaces of human teeth. Arch Oral Biol 1971;16:465-468.

4. American Academy of Periodontology. Sonic and ultrasonic scalers in periodontics (position paper). J Periodontol 2000;71:1792-1801.

5. Torfason T, Kinger R, Selving K, Egelberg J. Clinical improvement of gingival conditions following ultrasonic versus hand instrumentation of periodontal pockets. J Clin Periodontol 1979;6:165-176.

6. Boretti G, Zappa U, Graf H, Case D. Short-term effects of phase I therapy on crevicular cell population. JPeriodontol 1995;66:235-240.

7. Badersten A, Nilveus R, Egelberg J. Effect of nonsurgical periodontal therapy: III. Single versus repeated instrumentation. J Clin Periodontol 1984;11: 114-124.

8. Laurell L. Periodontal healing after scaling and root planing with the Kavo Sonicflex and Titan-S sonic scalers. Swed Dent J 1990;14:171-177.

9. Copulos TA, Low SB, Walker CB, Trebilcock YY, Hefti AF. Comparative analysis between a modified ultrasonic tip and hand instruments on clinical parameters of periodontal disease. J Periodontol 1993;64:694-700.

10. Crespi R, Barone A, Covani U. Histologic evaluation of three methods of periodontal root surface treatment in humans. J Periodontol 2005;76:476-481.

11. Blomlof JP, Blomlof LB, Lindskog SF. Smear removal and collagen exposure after non-surgical root planing followed by etching with EDTA gel preparation. $J$ Periodontol 1996;67:841-845.

12. Holbrook WP, Muir KF, Macphee IT, Ross PW. Bacteriological investigation of the aerosol from ultrasonic scalers. Br Dent J 1978; 144:245-247.

13. Crespi R, Romanos GE, Barone A, Sculean A Covani U. Er:YAG laser in defocused mode for scaling of periodontally involved root surface: An vitro pilot study. J Periodontol 2005;76:686-690.

14. Schwarz F, Sculean A, Berakdar M, Szathmari L, Georg T, Becker J. In vivo and in vitro effects of an Er:YAG laser, a GaAlAs diode laser, and scaling and 
root planing on periodontally diseased root surfaces: A comparative histologic study. Lasers Surg Med 2003; 32:359-366.

15. Frentzen M, Braun A, Aniol D. Er:YAG laser scaling of diseased root surfaces. JPeriodontol 2002;73:524-530.

16. Schwarz F, Putz N, Georg T, Reich E. Effect of an Er:YAG laser on periodontally involved root surfaces: An in vivo and in vitro SEM comparison. Lasers Surg Med 2001;29:328-335.

17. Crespi R, Barone A, Covani U. Effect of Er:YAG laser on disease root surfaces: An in vivo study. $J$ Periodontol 2005;76:1386-1390.

18. Ito K, Nishikata J, Murai S. Effects of Nd:YAG laser radiation on removal of a root surface smear layer after root planing: A scanning electron microscope study. J Periodontol 1993;64:547-552.

19. Watanabe H, Ishikawa I, Suzuki M. Clinical assessments of the erbium:YAG laser for soft tissue surgery and scaling. J Clin Laser Med Surg 1996;14:67-75.

20. Schoop U, Moritz A, Maleschitz P. The impact of Er:YAG laser irradiation on root surfaces: An in vitro evaluation. J Oral Laser Appl 2001;1:35-41.

21. Ando Y, Aoki A, Watanabe H, Ishikawa I. Bactericidal effect of erbium YAG laser on periodontopathic bacteria. Lasers Surg Med 1996;19:190-200.

22. Folwaczny M, Mehl A, Aggstaller H, Hickel R. Antimicrobial effects of 2.94 micron Er:YAG laser radiation on root surfaces: An in vitro study. $\underline{J \text { Clin Periodontol }}$ 2002;29:73-78.

23. Yamaguchi H, Kobayashi K, Osada R, et al. Effects of irradiation of an erbium:YAG laser on root surfaces. J Periodontol 1997;68:1151-1155.

24. Theodoro LH, Haypek P, Bachmann L, et al. Effect of Er:YAG and diode laser irradiation on the root surface: Morphological and thermal analysis. JPeriodontol 2003; 74:838-843.

25. Sculean A, Schwarz F, Berakdar M, Romanos GE, Arweiler NB, Becker J. Periodontal treatment with an
Er:YAG laser compared to ultrasonic instrumentation: A pilot study. J Periodontol 2004;75:966-973.

26. Schwarz F, Sculean A, Georg T, Reich E. Periodontal treatment with an Er:YAG laser compared to scaling and root planing. A controlled clinical study. J Periodontol 2001;72:361-367.

27. Schwarz F, Sculean A, Berakdar M, Georg T, Reich E, Becker J. Clinical evaluation of an Er:YAG laser combined with scaling and root planing for nonsurgical periodontal treatment. A controlled, prospective clinical study. J Clin Periodontol 2003;30:26-34.

28. Cobb CM. Laser in periodontics: A review of the literature. J Periodontol 2006;77:545-564.

29. Löe $H$. The gingival index, the plaque index and the retention index system. J Periodontol 1967;38:610-616.

30. Tomasi C, Kerstin S, Gunnar D, Wennstrom JL. Short-term clinical and microbiologic effects of pocket debridement with an Er:YAG laser during periodontal maintenance. J Periodontol 2006;77:111-118.

31. Frentzen $\bar{M}$, Braun A, Aniol D. Er:YAG laser scaling of diseased root surfaces. J Periodontol 2002;73: 524-530.

32. Crespi R, Romanos GE, Cassinelli C, Gherlone E. Effects of Er:YAG laser and ultrasonic system on fibroblast attachment to root surfaces: In vitro study. J Periodontol 2006;77:1217-1222.

33. Schwarz F, Sculean A, Berakdar M, Georg T, Reich E, Becker J. Periodontal treatment with an Er:YAG laser or scaling and root planing. A 2-year follow-up splitmouth study. J Periodontol 2003;74:590-596.

Correspondence: Dr. Roberto Crespi, Department of Dentistry, Vita Salute University, San Raffaele Hospital, Via Olgettina N. 48, 20123 Milan, Italy. E-mail: robcresp@ libero.it.

Submitted November 21, 2006; accepted for publication February 12, 2007. 